\title{
Determination of the Fatty Acid Profile of Breast Milk from Nursing Mothers in Bungoma County, Kenya
}

\author{
Virate J. Kiprop' ${ }^{1}$, Amy W. Girard ${ }^{2}$, Lilian A. Gogo ${ }^{1}$, Mary N. Omwamba ${ }^{1}$, Symon M. Mahungu ${ }^{\mathbf{1}^{*}}$ \\ ${ }^{1}$ Department of Dairy and Food Science and Technology, Egerton University, Egerton, Kenya \\ ${ }^{2}$ Rollins School of Public Health, Emory University, Atlanta, GA, USA \\ Email: smahungu@yahoo.com
}

Received 24 April 2016; accepted 27 June 2016; published 30 June 2016

Copyright (C) 2016 by authors and Scientific Research Publishing Inc.

This work is licensed under the Creative Commons Attribution International License (CC BY).

http://creativecommons.org/licenses/by/4.0/

(c) (i) Open Access

\begin{abstract}
The fatty acid profile in breast milk of nursing mothers who participated in a Cohort for Vitamin A (COVA) study at the fourth and ninth month of lactation was investigated. Breast milk samples were collected by manual expression and stored at $-20^{\circ} \mathrm{C}$ until analysis. The fat was extracted from the milk and methylated using the American Oil Chemists' Society (AOCS) Official Methods with modifications. The separation, identification and quantification of the fatty acid methyl esters was performed by gas chromatography coupled with mass spectrometry (GC-MS). Fat contents of human milk increased significantly between the fourth and ninth month of lactation 0.38 and 1.21 $\mathrm{mg} \cdot \mathrm{mL}^{-1}$ respectively; $\mathrm{P}<0.05$. The major fatty acids of breast milk fat at the 4 th month of lactation were oleic acid $(66.6 \%)$, followed by linoleic acid $(51.3 \%)$ and palmitoleic acid $(28.9 \%)$. However, at the 9th month, the major component was linoleic acid (58.1\%), followed by oleic acid $(30.9 \%)$ and stearic acid $(23.1 \%)$. The percentage average of the total saturated fatty acids at the 4th month $(16.62 \%)$ was significantly lower $(P<0.05)$ than the average percent of the total unsaturated FAs $(48.93 \%)$. Similarly, at the 9 th month the percentage average of the total saturated fatty acids $(15.18 \%)$ was significantly lower $(P<0.05)$ than the average percent of the total unsaturated FAs $(31.05 \%)$. The results obtained in this study demonstrated that the fat content in breast milk significantly increased in the 9 th compared to the 4th month of lactation. The fatty profile was also significantly different with the omega 6 being the dominant at the 9th month compared with the omega $\mathbf{- 9}$ being dominant at the 4 th month of lactation.
\end{abstract}

\section{Keywords}

Fatty acid Profile, Breast Milk, Nursing Mothers, Fatty Acid Methyl Esters, Lactation

\footnotetext{
${ }^{*}$ Corresponding author.
}

How to cite this paper: Kiprop, V.J., Girard, A.W., Gogo, L.A., Omwamba, M.N. and Mahungu, S.M. (2016) Determination of the Fatty Acid Profile of Breast Milk from Nursing Mothers in Bungoma County, Kenya. Food and Nutrition Sciences, 7, 661670. http://dx.doi.org/10.4236/fns.2016.78067 


\section{Introduction}

Breast milk is considered the ideal food for full-term infants: exclusive breast feeding for 6 months is considered to be a desirable goal [1]-[3]. Fat is a critical component of breast milk, providing energy and nutrients key to the development of the central nervous system, which cannot be synthesized de novo by the infant [1] [4] [5]. Human milk is not a static, invariant fluid, but fluctuates in micro- and macro-nutrient composition over the course of a feeding, longitudinally from birth to weaning, and, at least for some components, as a consequence of maternal diet [6]. For example, during the course of a single feed, total lipid concentration increases several fold from foremilk to hind milk [6] [7]. Fatty acids in breast milk may originate either from the recent dietary fatty acid intake, fatty acids released from maternal adipose tissue or further metabolism of dietary fatty acids in the maternal liver [8]. The fat content and fatty acid composition of human milk are variable. Milk's fatty acid composition is influenced by certain factors vis-à-vis diet, duration of pregnancy, maternal parity, and the stage of lactation [9] [10]. Maternal diet appears to be the most important variable determining milk's fatty acid composition [11] [12].

The milk fat is composed of $98 \%$ triacylglycerols (TAGs) and 1\% - 2\% phospholipids. This distribution may have functional consequences, since it has been reported that fatty acids from the phospholipid fraction could be driven directly to target tissues and membranes [13] [14]. Dietary differences between different countries or between regions of the same country have been reported to affect the composition of breast milk. Earlier estimates of fat content in breast-milk from well-nourished communities of the United States of America and Britain gave an average of $0.045-0.048 \mathrm{~g} / \mathrm{ml}$ [15]. However, results from poorly fed women in developing countries showed considerable variation and could sometimes be as low as $0.01 \mathrm{~g} / \mathrm{ml}$. This shows a drastic reduction in the energy content of milk, which may result in protein energy malnutrition (PEM) in the infants [10] [16]. Hence it was of interest to determine the fat content from Kenyan population. Examination of milk-lipid concentration and composition is of interest because milk fat provides the major fraction of calories in human milk [1] [6].

Changes in breast milk fatty acid profile and the TAGs content at different stages of lactation have been reported [17]-[19]. The work by [17] demonstrates that human milk produced during prolonged lactation ( $>1$ year) is extraordinarily rich in fat and has a higher energy content than human milk produced during the first half-year of lactation. Research by [18] found increasing fat contents with stable or increasing percentage contribution of long chain polyunsaturated fatty acids (LCPUFAs) in breast milk samples from the sixth week to the sixth month of lactation. The research by [19] found that the fatty acid profile of human milk during prolonged lactation ( $>1$ year) was not identical to that of human milk during short lactation ( 2 - 6 months). These researchers concluded that women who lactated for more than 1 year had a higher $\mathrm{C} 12$ and $\mathrm{C} 14$ fatty acid percentages in their milk than women who lactated for 2 - 6 months. The percentage contribution of arachidonic acid (AA) and docosahexaenoic acid (DHA) to breast milk lipids was reported to decrease with advancing duration of lactation. Despite the importance of human milk fatty acids for infant growth and development, there are few reports describing fatty acid profile of breast milk from developing countries. Therefore, the present study was designed to estimate the FA profile of breast milk of nursing mothers who were participating in a Cohort study of the impact of an integrated agriculture, nutrition and health intervention on the Vitamin A and health status of mothers and their infants from pregnancy through 9 months postpartum in Bungoma County, Kenya. The fatty acids were characterized and quantitated at the 4th and 9th month of lactation.

\section{Materials and Methods}

\subsection{Subjects}

The study subjects were healthy mothers (age 17 to 35 years) enrolled at mid pregnancy (10 - 24 weeks) and followed through 9 months postpartum, full term, health infant, exclusive breastfeeding for more than 9 months and residing in the catchment area. Participation was voluntary, and informed consent was obtained from the participants. The study was approved by the Kenya Medical Research Institute (KEMRI) and Emory Internal Review Board (EIRB). Milk was collected by manual expression by the mothers in a health facility and the breast milk (BM) samples were processed and kept at $-20^{\circ} \mathrm{C}$ prior to delivery and analysis at Egerton University Chemistry laboratory. 


\subsection{Sample Preparation (Milk Fat Extraction)}

The breast milk fat was extracted using AOAC 989.05 official method [20] with modifications. The frozen milk sample was thawed for 30 mins and then vortexed for 30 seconds. Two drops of butylated hydroxyl toluene (BHT) was mixed with $1 \mathrm{~mL}$ of milk and refluxed for $30 \mathrm{~min}$ after addition of $1 \mathrm{~mL}$ of $3 \mathrm{~N}$ hydrochloric acid and cooled. To this sample, $1 \mathrm{~mL}$ of $\mathrm{NH}_{4} \mathrm{OH}$ was added to neutralize the acidic sample and dissolve the casein followed by addition of 1 drop of phenolphthalein indicator to sharpen visual appearance between the ether and aqueous layers. To the neutralized sample, $1 \mathrm{~mL}$ of $95 \%$ ethanol was added and the flask vigorously shaken for $1 \mathrm{~min}$ while releasing built-up pressure. To the mixture, $2.5 \mathrm{~mL}$ of diethyl ether was added and sample shaken for $1 \mathrm{~min}$ to dissolve the lipids. To the extract, $2.5 \mathrm{~mL}$ petroleum ether was added and the mixture shaken for 1 min to separate water and dissolve more non polar lipids. The mixture was transferred to a separating funnel and left to stand for 20 minutes. The upper ether layer was then decanted into a weighed round bottomed flask. All the reagents used were of analytical grade. The solvent was evaporated to dryness on a hot plate in a hood at $100^{\circ} \mathrm{C}$ and dried to a constant weight in an oven at $100^{\circ} \mathrm{C} \pm 1^{\circ} \mathrm{C}$ and the percent fat for each sample was calculated as follows:

$$
\text { The } \% \text { fat }=100 \times\{[(\text { wt flask }+ \text { fat })-(\text { wt of flask })]-(\text { average wt blank residue })\} / \text { wt sample wt }=\text { weight }
$$

Note: For blank determinations, $1 \mathrm{~mL}$ of distilled water was used instead of milk sample.

\subsection{Preparation of Fatty Acid Methyl Esters}

Fatty acids were derivatized following the Official Methods of the American Oil Chemists' Society [21] with modifications. The breast milk fat was suspended in $2 \mathrm{~mL}$ hexane prior to derivatization. To the flask containing the fat, $5 \mathrm{~mL}$ of $0.5 \mathrm{~N}$ methanolic sodium hydroxide was added with a few boiling chips (anti bumping granules). Water cooled condenser was attached and refluxed on a heating plate for $1 \mathrm{hr}$. To the boiling mixture, 5 $\mathrm{mL}$ of boron tri fluoride $\left(\mathrm{BF}_{3}\right)$-Methanol $(10 \% \mathrm{vol} / \mathrm{vol})$ was added through the top of the condenser then refluxed for 30 minutes. About $5 \mathrm{~mL}$ of hexane was then added and refluxed for 1 min longer. While still attached to the condenser, the round bottom flask was raised above the heating plate and allowed to cool for 15 minutes. To the cooled extract, $10 \mathrm{~mL}$ of saturated sodium chloride $(\mathrm{NaCl})$ solution was added to the flask and stoppered after disconnecting the condenser. The contents were shaken vigorously for $2 \mathrm{~min}$ and left to stand for $10 \mathrm{~min}$ followed by additional $3 \mathrm{~mL}$ of saturated sodium chloride $(\mathrm{NaCl})$ to float the hexane layer. The hexane layer containing the methyl esters was transferred into a test tube with a small scoop of anhydrous sodium sulfate to dry the esters and the test tube then caped. The dried sample was transferred into a $2 \mathrm{~mL}$ vial and kept at $-4^{\circ} \mathrm{C}$ to await GC-MS analysis.

\subsubsection{Preparation of Sample for GC-MS Analysis}

To the sample in the vial, $1 \mathrm{~mL}$ hexane was added to the sample then vortexed for 30 seconds, followed by drying the sample by passing through anhydrous sodium sulfate $\left(\mathrm{Na}_{2} \mathrm{SO}_{4}\right)$ placed in a glass Pasteur pipette with a glass wool. The dried sample was transferred into Teflon caped vial from which $10 \mu \mathrm{L}$ was diluted by adding $990 \mu \mathrm{L}$ hexane then vortexed for 30 seconds. Two hundred $\mu \mathrm{L}$ of the mixture was pipetted into a clean Teflon caped sample vial with an insert. The vial was placed into an auto sampler where $1 \mu \mathrm{L}$ was injected into GCMS. All determinations were done in triplicates.

\subsubsection{Standard Preparation}

The stock solution was prepared by dissolving $10 \mathrm{mg} \cdot \mathrm{mL}^{-1}$ of the commercial FAMEs mixed standard into 100 $\mathrm{mL}$ of methylene chloride. Suitable volume of the stock solution of the FAMEs mixture was used for preparation of known concentrations (working standards).

\subsection{GC-MS Analysis}

The FAMEs were analyzed by splitless injection using an Agilent technologies-7890 gas chromatograph coupled to a 5975C inert XL EI/CI mass spectrometer (EI, $70 \mathrm{eV}$, Agilent, Palo Alto, California, USA). The GC was equipped with a carbowax HP-20M column $(25 \mathrm{~m} \times 0.20 \mathrm{~mm}$ ID $\times 0.20 \mu \mathrm{m}$ film thickness, Agilent, Palo Alto, California, USA), with helium as the carrier gas at a flow rate of $1.2 \mathrm{~mL} \cdot \mathrm{min}^{-1}$. The oven temperature was 
held at $35^{\circ} \mathrm{C}$ for 5 minutes, then programmed to increase at $10^{\circ} \mathrm{C} \cdot \mathrm{min}^{-1}$ to $220^{\circ} \mathrm{C}$ and maintained at this temperature for 10 minutes.

\subsection{Identification and Quantitation of FAMEs}

Fatty acid methyl esters were identified by comparison of retention times of the FAMEs from breast milk samples with retention times of commercial FAMEs standards and with library data (Adams2.L, Chemecol.L and NIST05a.L). The amount of triacylglycerol in the different breast milk samples was quantified based on peak areas. Data are reported for major fatty acids detected.

\subsection{Statistical Analysis}

Results are expressed as mean \pm standard error (SEM). For statistical analysis the R software (R version 3.1.1) [22] was used. The Wilcoxon signed rank test was used to detect the difference between the fatty acid composition of breast milk samples at the 4th month and the 9th month of lactation. The difference between the individual fatty acids and between samples at both lactation stages was also tested. The Kruskal-Wallis test was used for the difference between the various fatty acid groups identified. Results were considered significant at $\mathrm{P}<0.05$.

\section{Results and Discussion}

\subsection{Fatty Acids Analysis}

In the present study, the fatty acid methyl esters of breast milk were characterized. A total of 70 samples were analyzed for fatty acid profile. The major fatty acids identified and quantitated are shown in Table 1 . The acids are listed in order of elution on capillary column depending on their relative affinities. This result agrees with previous studies [6] [18] [19] [23]. Conversion factors (Table 1) were used to convert FAMEs concentrations to quantities of the breast milk fat as triacylglycerols (TAG) [24]. Concentrations of the identified fatty acids were calculated from the peak areas of corresponding FAME mixed standard using standard calibration curves. The fat content in the current study ranged from $0.010-0.065 \mathrm{~g} \cdot \mathrm{mL}^{-1}$ showing a slightly lower average as compared to the reports from Germany, US and Britain [15] [18]. The difference between our data and the others can be attributed to the difference in maternal diet as earlier reported [8] [25] [26].

The distribution of fatty acids during the 4th and 9th month of lactation is shown in Figure 1. Both stages of lactation were found to contain identical profile of fatty acids in the breast milk. However, the relative proportions were significantly different between mothers $(\mathrm{P}<0.001)$ and over the two stages of lactation $(\mathrm{P}<0.05)$. The fat content of the milk samples was significantly higher at the 9th month than at the 4th month of lactation (Table 2). More than $75 \%$ of the saturated fatty acids (SFA) were composed of C12:0 (lauric acid), C14:0 (myristic acid), C16:0 (palmitic acid), C18:0 (stearic acid) at both months. However, oleic acid (C18:1n-9) was the most abundant unsaturated fatty acid (66\%) at the 4th month while C18:2n-6 (linoleic acid, LA) was abundant

Table 1 . The major fatty acid methyl esters identified and quantified in the human milk.

\begin{tabular}{|c|c|c|c|c|c|}
\hline $\begin{array}{c}\text { FAME } \\
\text { IUPAC Name }\end{array}$ & $\begin{array}{c}\text { Common } \\
\text { Name (FA) }\end{array}$ & $\begin{array}{l}\text { Retention } \\
\text { Time (min) }\end{array}$ & No. of Carbons & $\begin{array}{c}\text { No. of double } \\
\text { Bonds }\end{array}$ & $\begin{array}{c}\text { Conversion } \\
\text { Factor }\end{array}$ \\
\hline Octanoic & Caprylic & 10.58 & 8 & 0 & 0.9915 \\
\hline Decanoic & Capric & 14.35 & 10 & 0 & 0.9928 \\
\hline Dodecanoic & Lauric & 16.97 & 12 & 0 & 0.9937 \\
\hline Tetradecanoic & Myristic & 19.17 & 14 & 0 & 0.9945 \\
\hline Hexadecanoic & Palmitic & 21.15 & 16 & 0 & 0.9950 \\
\hline 9-hexadecenoic & Palmitoleic & 21.36 & 16 & 1 & 0.9950 \\
\hline Octadecenoic & Stearic & 22.96 & 18 & 0 & 0.9955 \\
\hline 9-octadecenoic & Oleic & 23.11 & 18 & 1 & 0.9955 \\
\hline 9,12 octadecadienoic & Linoleic & 23.48 & 18 & 2 & 0.9954 \\
\hline
\end{tabular}




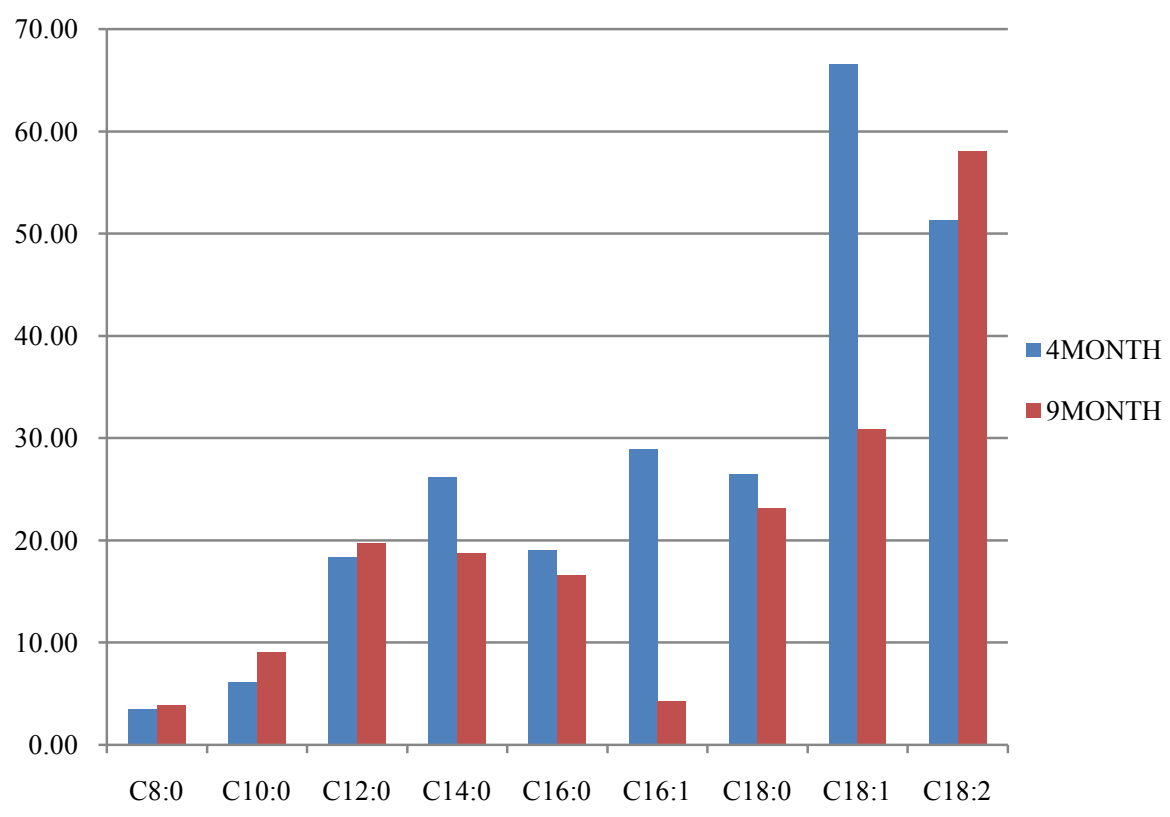

Figure 1. Changes in the percentage weight of fatty acids in breast milk at the 4th and 9th month of lactation.

Table 2. Fat content and percentage composition of the fatty acids in human milk of mothers investigated both at 4 th month and 9th month of lactation.

\begin{tabular}{cccccc}
\hline \multirow{2}{*}{ Fatty acid (FA) } & \multicolumn{2}{c}{ 4th month } & \multicolumn{2}{c}{ 9th month } \\
\cline { 2 - 5 } & Mean \pm SEM & n & Mean \pm SEM & $n$ \\
\hline Fat content $(\mathrm{mg} / \mathrm{ml})$ & $0.38 \pm 0.04$ & 35 & $1.21 \pm 0.003$ & 35
\end{tabular}

Fatty acid composition $(\% \mathrm{w} / \mathrm{w})$

Saturated fatty acids

$\begin{array}{ccccc}\text { C8:0 } & 3.52 \pm 2.17 & 20 & 3.82 \pm 0.88 & 20 \\ \text { C10:0 } & 6.16 \pm 1.79 & 35 & 9.05 \pm 4.98 & 35 \\ \text { C12:0 } & 18.35 \pm 6.65 & 35 & 19.70 \pm 8.33 & 35 \\ \text { C14:0 } & 26.14 \pm 9.62 & 35 & 18.77 \pm 8.71 & 35 \\ \text { C16:0 } & 19.04 \pm 6.03 & 35 & 16.53 \pm 6.56 & 35 \\ \text { C18:0 } & 26.47 \pm 6.13 & 35 & 23.14 \pm 5.02 & 35\end{array}$

Unsaturated fatty acids

C16:1n-7
C18:1n-9
C18:2n-6

Total saturated (Average)

Total unsaturated (Average)

Linolenic (C18:3n-3)

$28.88 \pm 23.49$
$66.59 \pm 26.48$
$51.32 \pm 13.59$
$16.62 \pm 4.00$
$48.93 \pm 10.95$
$\quad$ trace

$\begin{array}{lll}22 & 4.28 \pm 0.88 & 22 \\ 35 & 30.86 \pm 7.74 & 35 \\ 35 & 58.08 \pm 16.81 & 35\end{array}$

$15.18 \pm 2.97$

$31.05 \pm 15.51$

trace

Values are presented as mean \pm standard error (SEM). Proportion of each fatty acid measured in all the samples is significantly different $(\mathrm{P}<0.0001)$ at both lactation stages using Wilcoxon signed rank test $\mathrm{SEM}=\mathrm{S} / \sqrt{n}$ where $\mathrm{S}=$ sample standard deviation; $n=$ number of observations. 
unsaturated fatty acid (58\%) at the 9th month of lactation (Table 2). Researchers [27] separated, and tentatively identified TAGs by high performance liquid chromatograph (HPLC). These workers reported that the major TAGs were composed of 16:0, 18:1 and 18:2 regardless of variations in dietary fat. However, in the current study, we observed a significant increase for C8:0 - C12:0 fatty acids between the subjects at the two lactation stages, which was consistent with similar findings reported from Taiwan and Spain [23] [28]. These researchers observed an increased proportion of middle-chain fatty acids (MCFAs) compatible with the character of breast milk, presumably as the needs of infants' changed. These changes in milk composition may indicate variations in mammary gland biosynthetic capacity.

The importance of a high percentage of C12 (lauric acid) and C14 (myristic acid) in the diet of breast milk-fed infants may not be restricted to cholesterol metabolism and cardiovascular protection. Infants fed with human milk are notably protected against a multitude of infectious diseases, and it is possible that one of the many agents involved is indeed lauric acid [19]. The SFA mean found in breast milk at the 4th (16\%) and (15\%) at the $9^{\text {th }}$ month fell way below the European Range (ER) (39.0\% - 51.3\%) [29] and the (Granada) Spanish mature milk $(40.66 \%)$ [9]. Our study showed that stearic acid $\left(\mathrm{C}_{18: 0}\right)$ was the predominant saturated fatty acid that accounted more than $20 \%$ of the total fatty acids than palmitic $(19 \%$ and $16 \%)$ at the 4 th and 9 th month, respectively. Reference [19] also reported similar results where stearic acid (15\%) was the predominant SFA both at short and long lactation periods. This was however different from results of several studies, where the major saturated fatty acid, palmitic acid (C16:0), constantly accounted for 20\% of total fatty acids [9] [18] [23]. Dietary differences between different countries or between regions of the same country have been reported to affect the composition of human milk [8] [26] [30].

Oleic acid (C18:1n-9), the major monounsaturated fatty acid, and palmitoleic acid (C16:1n-7) decreased significantly at the 9th month, this agrees with similar findings reported from different geographic areas [9] [31]. Although oleic acid is not an essential fatty acid, it is very important because, in addition to the usual functions of fatty acids (source of energy and structural components), it reduces the melting point of triacylglycerols thus, providing the fluidity required for the formation, transport and metabolism of milk fat globules [25]. Figure 2 and Figure 3 shows representatives of total ion chromatograms of breast milk samples at the 4th and 9th month, respectively.

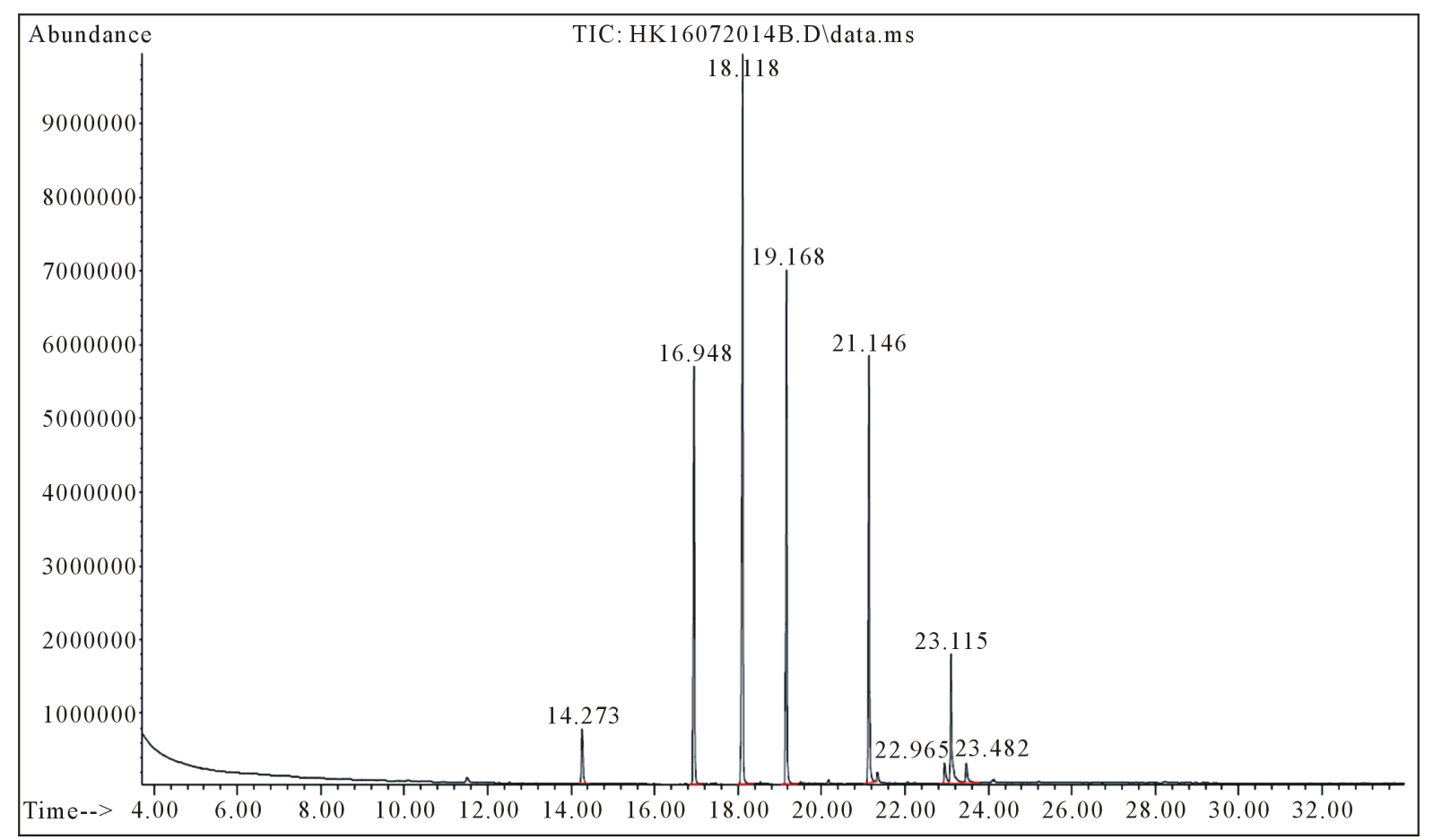

Figure 2. A representative of total ion chromatogram for a selected the 4th month BM sample produced using an Agilent technologies-7890 gas chromatograph coupled to a 5975C inert XL EI/CI mass spectrometer (EI, 70 eV, Agilent, Palo Alto, California, USA). 


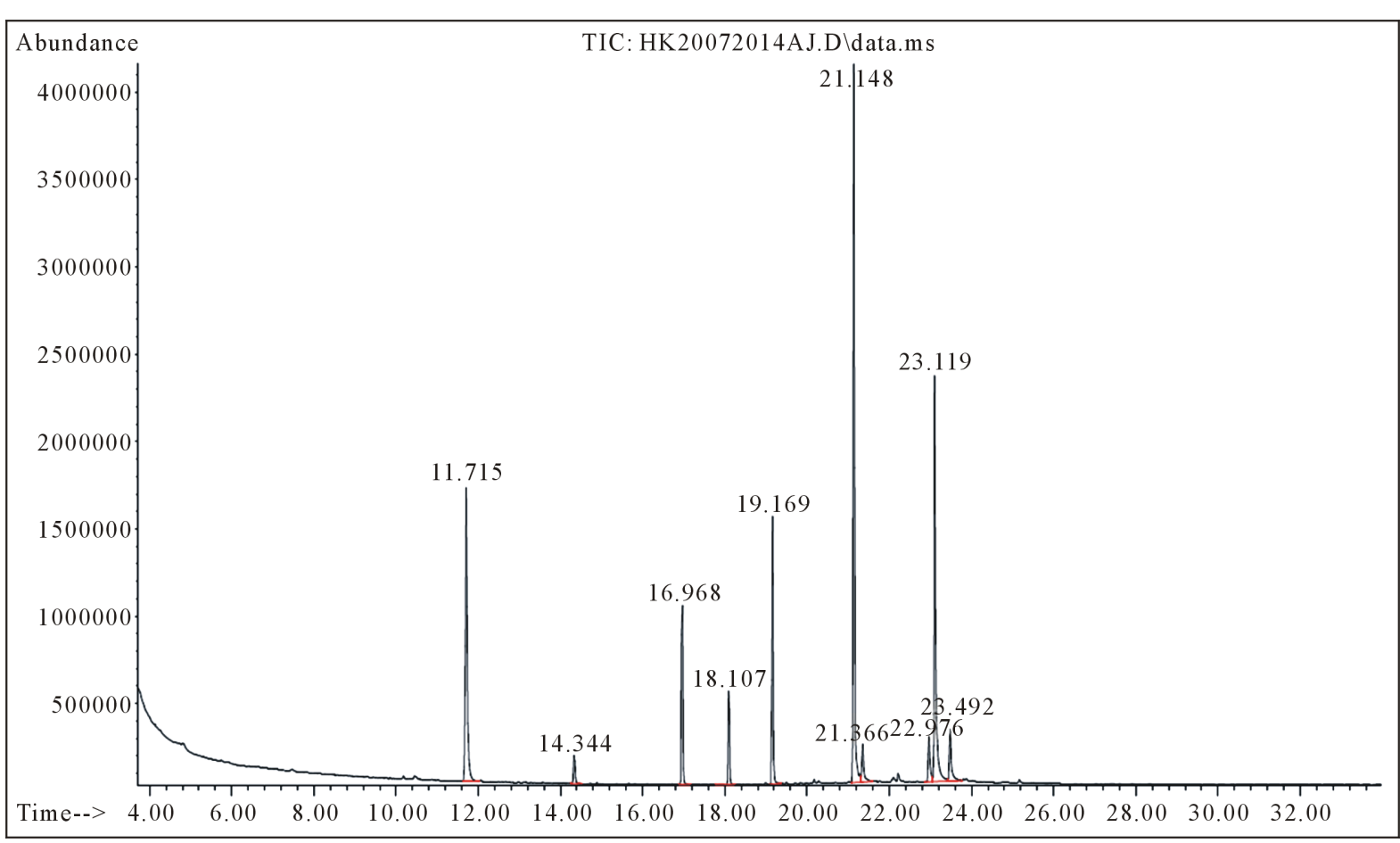

Figure 3. A representative of total ion chromatogram for a selected the 9th month BM sample produced using an Agilent technologies-7890 gas chromatograph coupled to a 5975C inert XL EI/CI mass spectrometer (EI, 70 eV, Agilent, Palo Alto, California, USA).

The LA mean values $(51.32 \%)$ at the 4 th and $(58.08 \%)$ at the 9th month were very high than the European range (6.9 - 16.4), German mean (10.6\%) [29] and Taiwanese mean value (23.62\%) [23]. These results suggest that Kenyan women from the analyzed group ingest a considerable amount of LA, mostly from vegetable oils such corn or sunflower, in their diet. The fact that the concentrations of $\alpha$-linolenic acid (ALA) were trace in all the samples analyzed was surprising to us. Indeed, generally reported concentrations of DHA in human milk range between 0.27 and 0.48 and are reported to be little influenced by maternal diet [32]. We must point out that Shehadah et al. [33] in a study of human milk during prolonged lactation also found undetectable values of docosahexaenoic acid (DHA) in the majority of samples. Similarly, Lubertzky et al. [19] in another study found that four fatty acids from the long chain polyunsaturated group were undetectable in a large percentage of samples and fell below the limit of detection of the method they used in their study.

The unsaturated fatty acids (C18:1 and $\mathrm{C} 18: 2)$ that were found to be predominant in the breast milk samples at both lactation periods may be a reflection of the dietary fat of the lactating mothers as earlier reported [34] [35]. The increase in mono and di-unsaturated fatty acids may be due to a reduction in the endogenous production of saturated fatty acids. An increase in polyenoic acids (unsaturated fatty acids) of breast milk due to substitution of corn oil for lard in the maternal diet had earlier been reported [36] [37]. Levels of LA in the breast milk from the present study were among the highest reported in the extensive literature characterizing breast-milk fatty acid composition hence of concern with regard to omega 3 fatty acids. Calder [38] reported that the high level of LA in Western diets has led to concern, particularly in relation to the concurrent low intake of n-3 fatty acids and the increasing prevalence of many inflammatory and immune disorders. The major portion of PUFA in milk, LA and AA, originate primarily from maternal fat stores, influenced by long-term dietary intake [8] [39]. LCPUFA (more than 20 carbon chains in length) are also synthesized from their respective precursors, LA and ALA, although conversion of arachidonic acid (AA), eicosapentaenoic acid (EPA) and docosahexaenoic acid (DHA) is low [39]. DHA conversion may also be diminished by competitive inhibition from LA and transFAs (TFAs) [39] [40]. Smit et al. [41] conducted an extensive evaluation of breast milk FA concentrations compared with regulatory standards and found that the levels of specific fatty acid (LA, ALA, AA, DHA, lauric acid, and myristic acid) from the milk of numerous mothers fell outside of the regulatory guidelines. Fatty acids should be considered as key nutrients that affect early growth and development and nutrition-related chronic 
disease in life [42] [43].

\section{Conclusions}

The results obtained in this study demonstrated that the FA composition varied among the 35 mothers and with time during the two lactation periods, most fatty acids decreasing in proportion at the 9th month of lactation. Stearic (C18), Myristic (C14), palmitic (C16), lauric (C12), oleic (C18:1) and linoleic (18:2) acids were the predominant fatty acids found at both lactation periods. Among the saturated fatty acids, stearic acid (C18:0) was the predominant fatty acid that accounted more than $20 \%$ of the total fatty acids while oleic acid constituted the primary monounsaturated FA in all samples. Human breast milk provides all the dietary essential fatty acids, linoleic acid (LA, C18:2n-6), an $\omega-6$ fatty acid and $\alpha$-linolenic acid (ALA, C18:3n-3), an $\omega-3$ fatty acid. However, our study showed that the ALA was undetectable or inadequate among the lactating women in the study population. Despite living in close physical proximity the nursing mothers showed distinct cultural difference in dietary intake as reflected in the difference in fatty acid composition of breast milk samples. The mothers were on ad libitum diets. It was interesting to note that the identified unsaturated FAs were in high concentration as compared to saturated FAs and were different between women, perhaps suggesting the dependence of these FAs on immediate diet as opposed to body depots.

Unsaturated fatty acids have one or more double bonds between carbon atoms (pairs of carbon atoms connected by double bonds can be saturated by adding hydrogen atoms to them, converting the double bonds to single bonds. Therefore, the double bonds are called unsaturated).

Saturated fatty acids have no double bonds. Thus, saturated fatty acids are saturated with hydrogen (since double bonds reduce the number of hydrogens on each carbon). Because saturated fatty acids have only single bonds, each carbon atom within the chain has 2 hydrogen atoms (except for the omega carbon at the end that has 3 hydrogens).

The differences in geometry between the various types of unsaturated fatty acids, as well as between saturated and unsaturated fatty acids, play an important role in biological processes, and in the construction of biological structures (such as cell membranes).

Omega-6 fatty acid is a polyunsaturated fat, essential for human health because it cannot be made in the body. For this reason, people must obtain omega- 6 fatty acids by consuming foods such as meat, poultry and eggs as well as nut and plant-based oils such as canola and sunflower oils. The double bond is in the sixth position from the omega end.

Omega-9 fatty acids are from a family of unsaturated fats that commonly are found in vegetable and animal fats. This monounsaturated fat is described as omega- 9 because the double bond is in the ninth position from the omega end.

\section{Acknowledgements}

This work was funded by a grant from the MAMA SASHA COVA Project and an Egerton University Council Graduate Student Scholarship. The GC-MS analyses were carried out at the International Centre of Insect Physiology and Ecology (Icipe), Nairobi.

\section{References}

[1] Lauritzen, L., Hansen, H.S., Jorgensen, M.H. and Michaelsen, K.F. (2001) The Essentiality of Long-Chain n-3 Fatty Acids in Relation to Development and Function of the Brain and Retina. Progress in Lipid Research, 40, 1-94. http://dx.doi.org/10.1016/S0163-7827(00)00017-5

[2] Gillman, M. (2002) Breast-Feeding and Obesity. Journal of Pediatrics, 141, 749-750. http://dx.doi.org/10.1067/mpd.2002.130168

[3] Gartner, L.M., Morton, J. and Lawrence, R.A. (2005) American Academy of Pediatrics Section on Breastfeeding. Breastfeeding and the Use of Human mil k. Pediatrics, 115, 496-506. http://dx.doi.org/10.1542/peds.2004-2491

[4] Koletzko, B., Rodriguez-Palmeroa, M., Demmelmaira, H., Fidler, N., Jensen, R. and Sauerwalda, T. (2001) Physiological Aspects of Human Milk Lipids. Early Human Development, 65, S3-S18. http://dx.doi.org/10.1016/S0378-3782(01)00204-3

[5] Agostoni, C., Brunetti, I. and Marco, A. (2005) Polyunsaturated Fatty Acids in Human Milk and Neurological Development in Breastfed Infants. Current Pediatric Reviews, 1, 25-30. http://dx.doi.org/10.2174/1573396052953435 
[6] Yuhas, R., Pramuk, K. and Lien, E.L. (2006) Human Milk Fatty Acid Composition from Nine Countries Varies Most in DHA. Lipids, 41, 851-858. http://dx.doi.org/10.1007/s11745-006-5040-7

[7] Koletzko, B., Mrotzek, M. and Bremer, H.J. (1986) Fat Content and Cis- and Trans-Isomeric Fatty Acids in Human Fore- and Hindmilk. Human Lactation: Maternal and Environmental Factors, 2, 589-594. http://dx.doi.org/10.1007/978-1-4615-7207-7 52

[8] Innis, S.M. (2007) Dietary (n-3) Fatty Acids and Brain Development. Journal of Nutrition, 137, 855-859.

[9] López-López, A., López-Sabater, M.C., Campoy-Folgoso, C., Rivero-Urgell, M. and Castellote-Bargallo, A. (2002) Fatty Acid and sn-2 Fatty Acid Composition in Human Milk from Granada (Spain) and in Infant Formulas. European Journal of Clinical Nutrition, 56, 1242-1254. http://dx.doi.org/10.1038/sj.ejcn.1601470

[10] Mitoulas, L.R., Gurrin, L.C., Doherty, D.A., Sherriff, J.L. and Hartmann, P.E. (2003) Infant Intake of Fatty Acids from Human Milk over the First Year of Lactation. British Journal of Nutrition, 90, 979-986. http://dx.doi.org/10.1079/BJN2003979

[11] Francois, C.A., Connor, S.L., Wander, R.C. and Connor, W.E. (1998) Acute Effects of Dietary Fatty Acids on the Fatty Acids of Human Milk. American Journal of Clinical Nutrition, 67, 301-308.

[12] Rodriguez, M., Koletzko, B., Kunz, C. and Jensen, R. (1999) Nutritional and Biochemical Properties of Human Milk, Part II. Lipids, Micronutrients and Active factors. Journal of Clinics in Perinatology, 26, 335-359.

[13] Giovannini, M., Riva, E. and Agostoni, C. (1995) Fatty Acids in Pediatric Nutrition. Pediatric Clinics of North America, 42, 861-877. http://dx.doi.org/10.1016/S0031-3955(16)39021-6

[14] Agostoni, C. (2008) Role of Long-Chain Polyunsaturated Fatty Acids in the First Year of Life. Journal of Pediatric Gastroenterology and Nutrition, 47, 41-44. http://dx.doi.org/10.1097/01.mpg.0000338811.52062.b2

[15] Macy, I.G. and Kelly, M.T. (1981) Fat in Today's Food Supply: Level of Use and Sources. The Journal of Pediatrics, 90, 67-72.

[16] Atkinson, S.A., Anderson, G.H. and Bryan, M.H. (1980) Human Milk: Comparison of the Nitrogen Composition in Milk from Mothers of Premature and Full Term Infants. The American Journal of Clinical Nutrition, 33, 811-815.

[17] Mandel, D., Lubetzky, R., Dollberg, S., Barak, S. and Mimouni, F.B. (2005) Fat and Energy Contents of Expressed Human Breast Milk in Prolonged Lactation. Pediatrics, 116, e432-e435. http://dx.doi.org/10.1542/peds.2005-0313

[18] Szabo, E., Boehm, G., Beermann, C., Weyermann, M., Brenner, H., Rothenbacher, D. and Decsi, T. (2010) Fatty Acid Profile Comparisons in Human Milk Sampled from the Same Mothers at the Sixth Week and the Sixth Month of Lactation. Journal of Pediatric Gastroenterology and Nutrition, 50, 316-320. http://dx.doi.org/10.1097/MPG.0b013e3181a9f944

[19] Lubetzky, R., Zaidenberg, G., Mimouni, B.F., Dollberg, S., Shimoni, E., Ungar, Y. and Mandel, D. (2012) Human Milk Fatty Acids Profile Changes during Prolonged Lactation: A Cross-Sectional Study. The Israel Medical Association Journal, 14, 7-10.

[20] AOAC (2005) Official Methods of Analysis. 16th Edition, Association of Official Analytical Chemists, Arlington.

[21] AOCS (2005) AOCS Official Method Ce 1-62. AOCS Press, Champaign.

[22] R Development Core Team (2011) R: A Language and Environment for Statistical Computing. R Foundation for Statistical Computing, Vienna. http://www.R-project.org

[23] Wu, T.C., Lau, B.H., Chen, P.H., Wu, L.T. and Tang, R.B. (2010) Fatty Acid Composition of Taiwanese Human Milk. Journal of the Chinese Medical Association, 73, 581-588. http://dx.doi.org/10.1016/S1726-4901(10)70127-1

[24] Nielsen, S.S. (2010) Food Analysis. Food Science Text Series. Springer, New York.

[25] Jensen, R.G. (1999) Lipids in Human Milk. Lipids, 34, 1243-1271. http://dx.doi.org/10.1007/s11745-999-0477-2

[26] Jirapinyo, P., Densupsoontorn, N., Wiraboonchai, D., Vissavavejam, U., Tangtrakulvachira, T., Chungsomprasong, P. and Thamonsiri, N. (2008) Fatty Acid Composition in Breast Milk from 4 Regions of Thailand. Journal of the Medical Association of Thailand, 91, 1833-1837.

[27] Dotson, K.D., Jerrell, J.P., Picciano, M.F. and Perkins, E.G. (1992) High-Performance Liquid Chromatography of Human Milk Triacylglycerols and Gas Chromatography of Component Fatty Acids. Lipids, 27, 933-939. http://dx.doi.org/10.1007/BF02535876

[28] Barbas, C. and Herrera, E. (1998) Lipid Composition and Vitamin E Content in Human Colostrum and Mature Milk. Journal of Physiology and Biochemistry, 54, 167-174.

[29] Koletzko, B., Thiel, I. and Philip, O. (1992) The Fatty Acid Composition of Human Milk in Europe and Africa. Journal of Pediatric, 120, 62-70. http://dx.doi.org/10.1016/S0022-3476(05)81238-7

[30] Golfetto, I., McGready, R., Ghebremeskel, K., Min, Y., Dubowitz, L. and Nosten, F. (2002) Fatty Acid Composition of Milk of Refugee Karen and Urban Korean Mothers. Is the Level of DHA in Breast Milk of Western Women Compro- 
mised by High Intake of Saturated Fat and Linoleic Acid? Annals of the New York Academy of Sciences, 967, 299-310.

[31] Pago-Gunsam, P., Guesnet, P., Subratty, A.H., Rajcoomar, D.A., Maurage, C. and Couet, C. (1999) Fatty Acid Composition of White Adipose Tissue and Breast Milk of Mauritian and French Mothers and Erythrocyte Phospholipids of Their Full-Term Breast-Fed Infants. British Journal of Nutrition, 82, 263-271.

[32] Koletzko, B. and Rodriguez-Palmeroa, M. (1999) Polyunsaturated Fatty Acids in Human Milk and Their Role in Early Infant Development. Journal of Mammary Gland Biology and Neoplasia, 4, 269-284. http://dx.doi.org/10.1023/A:1018749913421

[33] Shehadeh, N., Aslih, N., Shihab, S., Werman, M.J., Sheinman, R. and Shamir, R. (2006) Human Milk beyond One Year Post-Partum: Lower Content of Protein, Calcium, and Saturated Very Long-Chain Fatty Acids. The Journal of Pediatrics, 148, 122-124. http://dx.doi.org/10.1016/j.jpeds.2005.08.078

[34] Insull, W., Hirsch, J., James, T. and Ahrens, E.H. (1979) The Fatty Acids of Human Milk. The Journal of Clinical Investigation, 58, 443-446.

[35] Lassek, W.D. and Gaulin, S.J.C. (2006) Changes in Body Fat Distribution in Relation to Parity in American Women: A Covert Form of Maternal Depletion. American Journal of Physical Anthropology, 131, 295-302. http://dx.doi.org/10.1002/ajpa.20394

[36] Innis, S.M. and King, D.J. (1999) Trans Fatty Acids in Human Milk Are Inversely Associated with Levels of Essential All-Cis n-6 and n-3 Fatty Acids, and Determine Trans, but Not n-6 and n-3, Fatty Acids in Plasma of Breast-Fed Infants. The American Journal of Clinical Nutrition, 70, 383-390.

[37] Lawuyi, O., Spencer, E., Torimiro, A. and Fashakin, J.B. (2004) Effect of Lactation Period on Fatty Acid Profile of Breast Milk. Journal of Food, Agriculture \& Environment, 2, 59-61.

[38] Calder, P.C. (2006) Polyunsaturated Fatty Acids and Inflammation. Prostaglandins, Leukotrienes, and Essential Fatty Acids, 75, 197-202. http://dx.doi.org/10.1016/j.plefa.2006.05.012

[39] Brenna, J.T., Salem Jr., N., Sinclair, A.J. and Cunnane, S.C. (2009) [Alpha]-Linolenic Acid Supplementation and Conversion to n-3 Long-Chain Polyunsaturated Fatty Acids in Humans. Prostaglandins, Leukotrienes and Essential Fatty Acids, 80, 85-91. http://dx.doi.org/10.1016/i.plefa.2009.01.004

[40] Gibson, R.A., Muhlhausler, B., Makrides, M., Gibson, R.A., Muhlhausler, B. and Makrides, M. (2011) Conversion of Linoleic Acid and Alpha-Linolenic Acid to Long-Chain Polyunsaturated Fatty Acids (LCPUFAs), with a Focus on Pregnancy, Lactation and the First 2 Years of Life. Maternal \& Child Nutrition, 7, 17-26. http://dx.doi.org/10.1111/j.1740-8709.2011.00299.x

[41] Smit, E.C., Martini, I.A., Kemperman, R.F., Schaafsma, A., Maskiet, F.A. and Boersma, E.R. (2003) Fatty Acids in Formulae for Term Infants: Compliance of Present Recommendations with the Actual Human Milk Fatty Acid Composition of Geographically Different Populations. Acta Paediatrica, 92, 790-796. http://dx.doi.org/10.1111/j.1651-2227.2003.tb02534.x

[42] Uauy, R., Mize, C.E. and Duran, C.C. (2000) Fat Intake during Childhood: Metabolic Responses and Effects on Growth. The American Journal of Clinical Nutrition, 72, 1354-1360S.

[43] Hanson, L. and Korotkonva, M. (2002) Breast-Feeding May Boost Baby's Own Immune System. Pediatric Infectious Disease, 21, 816-821.

\section{Submit or recommend next manuscript to SCIRP and we will provide best service for you:}

Accepting pre-submission inquiries through Email, Facebook, Linkedin, Twitter, etc

A wide selection of journals (inclusive of 9 subjects, more than 200 journals)

Providing a 24-hour high-quality service

User-friendly online submission system

Fair and swift peer-review system

Efficient typesetting and proofreading procedure

Display of the result of downloads and visits, as well as the number of cited articles

Maximum dissemination of your research work

Submit your manuscript at: http://papersubmission.scirp.org/ 